\title{
THE
}

$1-2009$

\section{Heterogeneous Transport Costs and Spatial Sorting in a Model of New Economic Geography}

Corey Lang

University of Rhode Island, clang@uri.edu

Follow this and additional works at: https://digitalcommons.uri.edu/enre_facpubs

Part of the Agricultural and Resource Economics Commons

Terms of Use

All rights reserved under copyright.

\section{Citation/Publisher Attribution}

Lang, C. (2010), Heterogeneous transport costs and spatial sorting in a model of New Economic Geography. Papers in Regional Science, 89: 191-202. doi: 10.1111/j.1435-5957.2009.00245.x

This Article is brought to you for free and open access by the Environmental and Natural Resource Economics at DigitalCommons@URI. It has been accepted for inclusion in Environmental and Natural Resource Economics Faculty Publications by an authorized administrator of DigitalCommons@URI. For more information, please contact digitalcommons-group@uri.edu. 


\title{
Heterogeneous Transport Costs and Spatial Sorting in a Model of New Economic Geography*
}

\author{
Corey Lang \\ Cornell University, Department of Economics \\ 404 Uris Hall, Ithaca, NY 14853 \\ Email: CL395@cornell.edu \\ Fax: 607-255-2818
}

January 29, 2009

\begin{abstract}
Transportation costs are of central importance in the New Economic Geography literature, though assumptions about transportation costs continue to be simplistic. This paper begins to address these simplifications by assuming that transportation costs for manufactured goods are heterogeneous. Basic results are consistent with standard models showing dispersion of economic activity for high transport costs and eventual agglomeration as transport costs decline. However, several novel features arise too. Many unstable, dispersed equilibria exist for high average transport costs, but converge to a stable equilibrium path as transport costs decrease. Equilibrium paths smoothly transition from dispersion to agglomeration and do so at an increasing rate. Additionally, transport costs directly influence firms' location decisions and firms spatially sort by transport cost.
\end{abstract}

JEL classification: R12, F12, F20

Keywords: Economic geography, transport costs, sorting, agglomeration Running Title: Heterogeneous transport costs and NEG

\footnotetext{
* I would like to thank Jeff Larrimore, Max Mihm, Russell Toth, seminar participants at Cornell University and three anonymous referees for helpful comments. I especially appreciate the guidance and suggestions received from Kieran Donaghy.
} 


\section{Introduction}

This paper seeks to add to our understanding of the role of transportation costs in New Economic Geography (NEG) models by specifically modeling firms with heterogeneous transport costs in an NEG framework. There are two main reasons to examine this situation: 1) transport costs play a critical role in NEG models and need to be explored in more depth and 2) products in the real world clearly have different transport costs.

In general, NEG models examine how the spatial distribution of economic activity changes as transportation costs slowly decline. ${ }^{1}$ The slow decline is meant to mirror the actual decline in transportation costs observed over the modern era of civilization. As transportation costs fall, firms are able to export goods more cheaply and thus become less tied to immobile factors as sources of profit. This sets off a circular causality between mobile firms and mobile consumers. Each find it in their best interest to locate where the other exist, leading to agglomeration of all mobile economic activity.

NEG models generally have two sectors, manufacturing and agriculture, and typically all firms in manufacturing have identical transport costs and agricultural commodities are costless to trade. Given the importance of transportation costs in NEG models, several papers explore alternative assumptions (e.g. costly agricultural transport, Davis (1998); tariffs versus trade liberalization, Puga and Venables (1999); congestion effects, Lanaspa and Sanz (2001)). More related to the current paper, Alonso-Villar (2005) extends Venables's (1996) model to allow the transport cost of final

\footnotetext{
${ }^{1}$ The seminal papers are Krugman (1991) and Venables (1996). Neary (2001) and Fujita and Mori (2005) offer good reviews.
} 
manufacturing goods to differ from that of intermediate manufacturing goods. ${ }^{2}$ She finds that the spatial distribution of firms can evolve in completely opposite ways depending on which of the two transport costs decrease. Amiti (1998), though not using an NEG framework but closely related, analyzes a model with two countries which differ in size and two manufacturing industries which differ in transport cost. She finds that the large country specializes in the production of the high transport cost good in order to have access to the larger market without paying shipping costs.

Common sense suggests that different goods have different transport costs in the real world. Hummels (2001) clearly demonstrates just this by calculating average freight charges for 2-digit SIC codes for several countries. In general, however, there is a dearth of empirical research in this area. Anderson and van Wincoop (2004) argue this is because "direct measures [of trade costs] are remarkably sparse and inaccurate." As a result, estimation strategies that measure aggregate trade costs for an entire country or time period are necessary, such as a gravity model.

The purpose of this paper is to determine the effects of assuming that each firm pays a different export cost in an NEG framework. Do traditional results of agglomeration and dispersion still hold? Does agglomeration occur all at once (catastrophically) for a threshold transport cost or more smoothly and why? Does a firm's transport cost influence its location decision and why? I address these questions using a linear footloose entrepreneur model, which comes from a variation of the linear model by Ottaviano et al. (2002) proposed and solved by Baldwin et al. (2003). ${ }^{3}$ There

\footnotetext{
${ }^{2}$ Rossi-Hansberg (2005) takes a similar approach in a non-NEG setting.

${ }^{3}$ Forslid and Ottaviano (2003) first introduced the footloose entrepreneur model, though they use a setup more akin to Krugman (1991). Pflüger and Südekum (2008) offer a synthesis of footloose entrepreneur NEG models.
} 
are two regions, two sectors, and two types of labor, entrepreneurs and laborers.

Entrepreneurs work in manufacturing and are mobile across regions, whereas laborers are immobile and work in both sectors.

Several other papers introduce heterogeneities into NEG models for interesting results. Tabuchi and Thisse (2002) and Murata (2003) assume consumers have heterogeneous preferences over levels of an exogenously set public good. Zeng (2008), on the other hand, examines a situation in which consumers have heterogeneous preferences over privately consumed goods. All three papers conclude that the heterogeneities act as a strong dispersion force and can cause segregation of consumers by preferences. ${ }^{4}$ In an entirely different vein, Baldwin and Okubo (2006) assume firms' productivity is heterogeneous and show how a process of selection can overstate econometric estimates of the benefits to agglomeration.

The results of the present model prove to be a fruitful extension of the standard framework as well. Like the standard results, the distribution of firms is dispersed for high transport costs and agglomerated for low transport costs. However, multiple unstable equilibria exist for high transport costs and, as transport costs decrease, the equilibria converge to one of two stable equilibrium paths which tend toward agglomeration smoothly. ${ }^{5}$ No stable equilibrium exists for high transports costs and only stable (and agglomerated) equilibria exist for low transport costs.

\footnotetext{
${ }^{4}$ Alonso-Villar (2008) offers a nice discussion of how results such as these are driven by a combination of two separate dispersion forces. In the three papers mentioned, there is the standard demand-pull dispersion force from the immobile laborers/farmers as well as the heterogeneous preferences that act as an additional dispersion force. Alonso-Villar (2008) produces a bell-shaped distribution pattern - i.e. dispersion for low and high transport costs and agglomeration in between - by introducing consumer congestion costs into a standard framework that already includes a demand-pull element.

${ }^{5}$ Several other papers have produced results with smooth equilibrium paths (e.g. Puga 1999).
} 
In addition, firms sort and segregate themselves by transport cost creating a high transport cost region and a low transport cost region. The bifurcation does not develop immediately, but once firms are sorted they remain that way. Agglomeration always occurs in the region which establishes itself as the low transport cost region.

The paper proceeds as follows. Section 2 presents the model, discusses the entrepreneurs' key role and motivations for their location decisions, and defines equilibrium and stability concepts. In section 3, I describe how numerical methods are used to solve the model. I discuss and illustrate the results in section 4, and also explain the causes and effects of the opposing agglomeration and dispersion forces. Section 5 concludes.

\section{Model}

There are two regions, Home $(\mathrm{H})$ and Foreign $(\mathrm{F})$. Each region has two sectors, which will be referred to as Agriculture and Manufacturing. ${ }^{6}$ There are two inputs to production: entrepreneurs and labor. There are $\mathrm{N}$ entrepreneurs total; they only work in manufacturing and are mobile across regions. The L laborers, on the other hand, work in both sectors, are immobile across regions and are evenly split between regions.

There are two goods in the economy corresponding to the two sectors. The agricultural good is homogenous and is produced using constant returns to scale technology under perfect competition. Additionally, all individuals are endowed with a positive amount of this good.

\footnotetext{
${ }^{6}$ These names are more for expositional purposes than truly representing those sectors. It is most important that we accept that there are production inputs which are mobile or tradable and inputs which are not.
} 
The second good, manufactures, is a composite of $\mathrm{N}$ horizontally differentiated manufacturing goods. ${ }^{7}$ The market for manufactures is described as monopolistic competition, where each firm supplies a differentiated product. $\mathrm{N}$ is large such that each firm has a negligible impact on the market. However, aggregate market conditions, specifically the price index of a region, do affect demand facing a firm. All interactions between firms are non-strategic and there is free entry into the market. All firm profits are equally distributed to all residents of a region.

Individuals are either entrepreneurs or laborers; both earn wages for their labor that they supply inelastically. Regardless of their type, all individuals are consumers and have identical preferences, which are described by the quasi-linear quadratic utility function

$$
\begin{aligned}
& U\left(q_{1}, \ldots, q_{N}, q_{A}\right)=\alpha \sum_{i=1}^{N} q_{i}+\frac{\beta-\delta}{2} \sum_{i=1}^{N} q_{i}^{2}-\frac{\delta}{2}\left(\sum_{i=1}^{N} q_{i}\right)^{2}+q_{A} \\
& 0<\alpha, 0<\delta<\beta
\end{aligned}
$$

where $q_{i}$ is consumption of the $i^{\text {th }}$ manufacturing good and $q_{A}$ is consumption of the agricultural good. In the utility function, $\alpha$ expresses the intensity of preferences for a differentiated product, $\delta$ measures the substitutability of the goods (higher $\delta$, closer substitutes), whereas $\beta>\delta$ implies that consumers prefer variety. The budget constraint for a consumer, given wages y and initial endowment $q_{0}$, is

$$
\sum_{i=1}^{N} p_{i}^{H} q_{i}+p_{A}^{H} q_{A}=y+q_{0}+\pi_{c}^{H}
$$

\footnotetext{
${ }^{7}$ Usually, the number of goods is considered to be a continuum instead of a finite number. The usual assumption ensures that firms earn zero profit in equilibrium. However, if this model allowed for a continuum of firms and free entry, then only those firms with the cheapest transport costs would remain in equilibrium. This result does not match reality where firms survive based primarily on consumer demand, not their transport cost. In this model, one of the factors of production, entrepreneurial talent, is scarce and it is by this means that each firm earns zero profit in equilibrium.
} 
where $p_{i}^{H}$ is the price of manufactured good $i$ in region $\mathrm{H}, p_{A}^{H}$ is the price of the agricultural good in region $\mathrm{H}$, and $\pi_{c}^{H}$ is the individual share of profit. Prices are region specific such that the budget constraints of the two regions are usually not the same. I will refer to prices (and any variable in general) in Home with an $\mathrm{H}$ superscript and prices in Foreign with an F superscript. The equations written here are from Home's perspective, but equations for Foreign could easily be written in the same manner. The endowment $q_{0}$ is large enough such that $q_{A}>0$ for all consumers in equilibrium. After solving the consumer maximization problem and making a change of variables, the demand for a single manufacturing variety can be written as

$$
\begin{aligned}
& q_{i}\left(p_{i}^{H}, P^{H}\right)=a-(b+c N) p_{i}^{H}+c P^{H} \\
& \quad a=\frac{\alpha}{\beta+\delta(N-1)}, b=\frac{a}{\alpha}, c=\frac{\delta b}{\beta-\delta}, P^{H}=\sum_{i=1}^{N} p_{i}^{H}
\end{aligned}
$$

$P^{H}$ is referred to as the price index.

An expression for indirect utility is derived by substituting the demand equations into the utility function:

$$
\begin{aligned}
V\left(p_{1}^{H}, \ldots, p_{N}^{H}, y, q_{0}\right) & =\frac{a^{2} N}{2 b}-a \sum_{i=1}^{N} p_{i}^{H}+\frac{b+c N}{2} \sum_{i=1}^{N}\left(p_{i}^{H}\right)^{2}-\frac{c}{2}\left(\sum_{i=1}^{N} p_{i}^{H}\right)^{2}+y+q_{0}+\pi_{c}^{H} \\
& =\frac{a^{2} N}{2 b}-a P^{H}-\frac{c\left(P^{H}\right)^{2}}{2}+\frac{b+c N}{2} \sum_{i=1}^{N}\left(p_{i}^{H}\right)^{2}+y+q_{0}+\pi_{c}^{H}
\end{aligned}
$$

The technology available to both regions is identical. The marginal labor requirement of Agriculture is denoted $a_{A}>0$. Since there is perfect competition in this sector, the agricultural good sells for marginal cost, that is $p_{A}^{H}=a_{A} w_{L}^{H}$ and $p_{A}^{F}=a_{A} w_{L}^{F}$. Further, this good can be traded between the regions without incurring transport cost. 
Thus, arbitrage guarantees that prices equalize, $p_{A}^{H}=p_{A}^{F}$. I let agriculture be the numeraire good so that $p_{A}^{H}=p_{A}^{F}=1$. This implies that nominal wages for labor are $w_{L}=w_{L}^{H}=w_{L}^{F}=1 / a_{A} ;$ real wages depend on the price index.

Manufacturing production requires a fixed cost of one entrepreneur and labor is a variable input. Each entrepreneur is associated with a given manufacturing good and that good's corresponding transport cost. A firm's product and transport cost is determined by the entrepreneur that it hires. Each firm needs $a_{M}>0$ units of labor for each unit of output. The total cost of production for firm $i$ producing $q_{i}$ units is $w_{i}+a_{M} w_{L} q_{i}$ where $w_{i}$ is the wage of the $i^{\text {th }}$ entrepreneur. The cost structure implies increasing returns to scale at the firm level. Firm $i$ can export one unit of its product to the other region for a positive cost of $\tau_{i}$ units of the numeraire good, where $\tau_{i}$ accounts for all impediments to trade and does not depend on the location of the firm. Transport costs are uniformly distributed over range $\mathrm{R}$ (i.e. $\left.\tau_{i+1}-\tau_{i}=R / N \forall i<N\right){ }^{8} \quad$ The profit of a firm located in Home is

$$
\begin{aligned}
& \pi_{i}^{H}\left(\tau_{i}, w_{i}, N, S^{H}, S^{F}, P^{H}, P^{F}\right)= \\
& \operatorname{Max}_{\left\{p_{i}^{H i}, p_{i}^{H F}\right\}}\left(p_{i}^{H H}-a_{M}\right) S^{H}\left(a-(b+c N) p_{i}^{H H}+c P^{H}\right)+ \\
&\left(p_{i}^{H F}-a_{M}-\tau_{i}\right) S^{F}\left(a-(b+c N) p_{i}^{H F}+c P^{F}\right)-w_{i} .
\end{aligned}
$$

The firm sets prices for its product in Home $\left(p_{i}^{H H}\right)$ and in Foreign $\left(p_{i}^{H F}\right)$. The first letter in the superscript denotes where the product is manufactured and the second denotes where it is consumed. If the firm was located in Foreign, it would instead set prices $p_{i}^{F F}$

\footnotetext{
${ }^{8}$ The manner in which $\tau_{\mathrm{i}}$ is distributed does not substantially affect results. All that really matters is that there is an ordinal relationship between firms; this should become clear when the results are discussed in section 5 .
} 
and $p_{i}^{F H} . S^{H}$ and $S^{F}$ are the sizes of the market (number of consumers) in Home and Foreign, respectively. If there are $N^{H}$ entrepreneurs in Home and $N^{F}$ in Foreign, then $S^{H}=L / 2+N^{H}$ and $S^{F}=L / 2+N^{F}$. No arbitrage opportunities exist as long as $p_{i}^{H F} \leq p_{i}^{H H}+\tau_{i}$, which holds true in equilibrium.

Entrepreneurial talent is a scarce resource and because there is free entry for firms entrepreneurial wages are bid up to the point that profit equals zero for all firms. I denote the portion of profit excluding entrepreneurial wage for firm $i$ in region $k$ as $\tilde{\pi}_{i}^{\mathrm{k}}\left(\right.$ i.e. $\left.\pi_{i}^{\mathrm{k}}=\tilde{\pi}_{i}^{\mathrm{k}}-w_{i}\right)$. Thus, an entrepreneur will choose a location where $\tilde{\pi}_{i}^{\mathrm{k}}$ is maximized, all else equal. I refer to this aspect of location preference as the profit effect. $\tilde{\pi}_{i}$ differs by location because of differences in the magnitude of consumer demand, the market access effect, and differences in the level of competition, the market crowding effect. Also, $\tilde{\pi}_{i}$ is different for different entrepreneurs because transport costs are heterogeneous, $\tilde{\pi}_{i}^{\mathrm{k}}>\tilde{\pi}_{j}^{\mathrm{k}} \Leftrightarrow \tau_{i}<\tau_{j} \forall i, j \in N$ and $k=H, F$.

Since entrepreneurs are also consumers, they also base their location decisions on local prices of manufacturing goods. The consumer effect, or cost of living effect, is the aspect of location preference that describes how an entrepreneur responds to differences in consumer welfare between the two regions. Consumer welfare is defined here as the portion of indirect utility derived from the consumption of manufactured goods. This effect is driven by consumer preferences for variety and motivates the entrepreneur to locate where prices are lowest and they can consume the most. 
An entrepreneur chooses a location by weighing the benefits of each location

from both the perspective of a consumer and a profit maximizer. Formally, entrepreneur $i$ chooses location $k$ where

$$
k=\underset{k=H, F}{\arg \max } V\left(p_{1}^{k}, \ldots, p_{N}^{k}, \tilde{\pi}_{i}^{k}, q_{0}\right) \quad \forall i \in N
$$

Wage is simultaneously determined with location such that $w_{i}=\tilde{\pi}_{i}^{k}$. The interaction between the profit effect and the consumer effect drive the results of the model and will be discussed more in section 4 with respect to specific results.

Short-run equilibrium is defined as a set of prices and allocations such that firms maximize profit, consumers maximize utility, and all markets clear. In the long term, entrepreneurs are able to relocate to the other region. I assume that all agents are myopic and seek to maximize current welfare. The law of motion that describes the aggregate migration of entrepreneurs is as follows: each period, rank from most to least the welfare gains each entrepreneur would receive by relocating and allow the top $\theta \%$ to move, the remainder of entrepreneurs do not move that period. ${ }^{9}$ A long-run equilibrium is defined as a short-run equilibrium in which no entrepreneur wishes to move. A long-run equilibrium is stable if a small permutation in the distribution of firms does not cause the equilibrium to change.

\section{Solving the model}

The first order conditions from the profit maximization problem can be used to solve for a firm's optimal prices in each location.

\footnotetext{
${ }^{9}$ The law of motion places a constraint on Equation 6 above, namely that in order for entrepreneur $i$ to be given the choice of location, their welfare differential must be in the top $\theta \%$. In equilibrium, equation 6 holds for all entrepreneurs.
} 


$$
\begin{aligned}
& p_{i}^{H H}=\frac{a+c P^{H}+a_{m}(b+c N)}{2(b+c N)} \\
& p_{i}^{F F}=\frac{a+c P^{F}+a_{m}(b+c N)}{2(b+c N)} \\
& p_{i}^{H F}=\frac{a+c P^{F}+\left(a_{m}+\tau_{i}\right)(b+c N)}{2(b+c N)}=p_{i}^{H H}+\frac{\tau_{i}}{2} \\
& p_{i}^{F H}=\frac{a+c P^{H}+\left(a_{m}+\tau_{i}\right)(b+c N)}{2(b+c N)}=p_{i}^{F F}+\frac{\tau_{i}}{2}
\end{aligned}
$$

where the price indices are:

$$
\begin{aligned}
& P^{H}=\sum_{i=1}^{N} p_{i}^{H}=\sum_{i=1}^{n} p_{i}^{H H}+\sum_{i=1}^{n^{*}} p_{i}^{F H} \\
& P^{F}=\sum_{i=1}^{N} p_{i}^{F}=\sum_{i=1}^{n} p_{i}^{H F}+\sum_{i=1}^{n^{*}} p_{i}^{F F}
\end{aligned}
$$

Clearly, each firm's optimal prices depend on the price indices. However, the price indices are a function of each firm's price. Thus, these equations must be solved simultaneously. When each firm has an identical transport cost, this problem reduces to solving a six-equation system. With heterogeneous transport costs though, it would be a system of 2(N+1) equations. I use numerical approximation to determine prices; profit and welfare levels follow directly from prices.

I simulate the model as follows. Given a starting distribution for the firms, the program solves for prices, which then indicate welfare levels. The program then checks for each entrepreneur if they individually would be better off in the other region, all else equal. Then the law of motion chooses which entrepreneurs migrate. Once again, prices and welfare are calculated for the new distribution of entrepreneurs. This iterative process is repeated until no single entrepreneur has the incentive to migrate. The resulting distribution is an equilibrium. Next, the stability of that equilibrium is tested. One at a time, each entrepreneur is switched to the opposite region and the iterative 
process of finding an equilibrium is repeated with the slightly perturbed equilibrium distribution as the starting distribution. If the resulting equilibrium is the same as the original equilibrium for every one-entrepreneur-perturbation, then the equilibrium is stable. All of this analysis is done for a single distribution of transport costs. Next the transport costs are uniformly lowered and the process of finding an equilibrium and checking its stability is repeated. The process is repeated for a range of transport costs until a complete equilibrium path is mapped out. An equilibrium path is a record of all equilibria for various transport costs stemming from a given initial distribution.

\section{Results}

The results are consistent with standard NEG models with homogenous transport costs. For high average transport costs, relatively equal dispersion of economic activity is observed, whereas for low average transport costs, agglomeration is observed. However, several novel features arise. For high average transport costs, many equilibria exist, all of which are close to symmetric dispersion and unstable. As average transportation costs decline, the multiple equilibrium paths converge to a common, stable path. Equilibrium paths smoothly transition from dispersion to agglomeration and they progress to complete agglomeration at an increasing rate. Finally, as average transportation costs decrease, entrepreneurs spatially sort themselves into high and low transport cost regions. Agglomeration always occurs in the region which establishes itself as the low transport cost region.

I discuss in detail below the major features of the model as well as explain the results in terms of the interaction between the profit effect, a dispersion force, and the 
consumer effect, an agglomeration force. Tension between dispersion and agglomeration forces is universal in NEG models. Transportation costs determine the relative strength of the two forces and agglomeration eventually dominates dispersion as transportation costs decline. In my model, not only does the relative importance of the two effects change as transport costs change, but the relative importance is different for each entrepreneur leading to differences in behavior.

From now on, I will use the terms firm and entrepreneur somewhat interchangeably. Regardless of whether I am discussing an entrepreneur or a firm migrating, it is always the entrepreneur's welfare that drives location decisions.

Figure 1 illustrates characteristic equilibrium paths. Refer to the Appendix for parameter values used to generate this graph and further details on the simulation. The dotted lines represent unstable equilibrium paths and the solid lines represent stable equilibrium paths. Note that not all equilibrium paths are graphed; more equilibria exist for high average transport costs. They are not shown because 1) the proportions are not significantly different (or different at all) than equilibria displayed and 2) they would clutter the diagram. Two equilibria can have identical proportions of firms in one region and still be different because of the heterogeneities in the model. 


\section{Characteristic equilibrium paths}

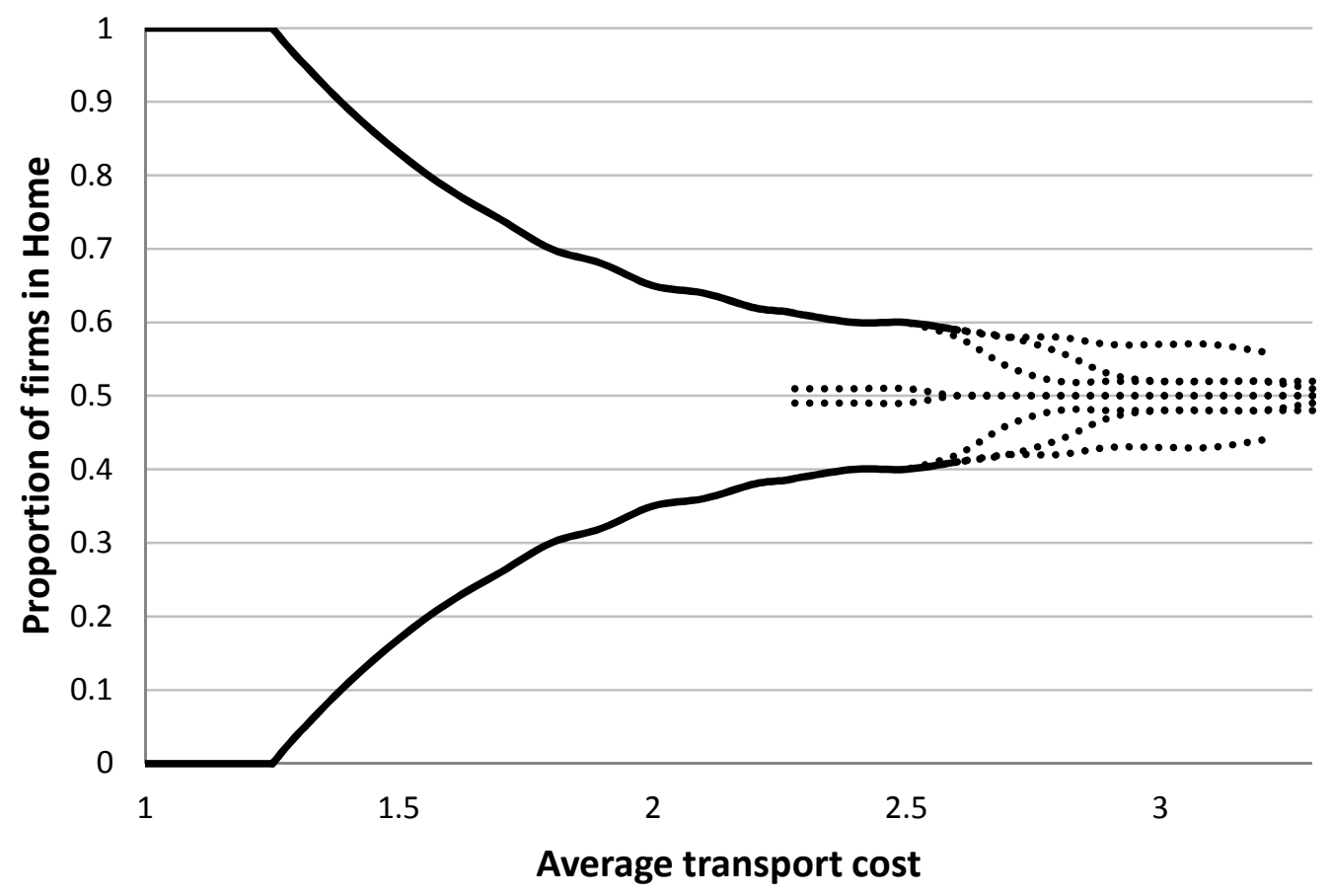

Figure 1. Characteristic equilibrium paths with heterogeneous transport costs. Dotted lines represent unstable equilibria and solid lines represent stable equilibria. Refer to the appendix for details of the specification.

The results are generally consistent with those from standard homogenous transport cost models. For high levels of transport cost, the equilibrium paths all have approximately or exactly an equal share of firms in each region. For low levels of transport cost, the only equilibria are agglomerated. However, there are important differences in the results that demonstrate the richness of the addition of heterogeneous transport costs.

IV.a. Multiple equilibrium paths

There are many equilibrium paths for high levels of transportation costs and all of the equilibria are unstable. To a large extent, these paths are sensitive to the initial distribution, though only up to a certain point. As transportation costs decline, the equilibrium paths converge and initial conditions become irrelevant. However, 
equilibrium paths also exhibit hysteresis. In the event of a trade cost reversal, equilibrium paths do not necessarily retrace the paths they took when costs were declining. Unlike the hysteresis of Krugman (1991) though, if trade costs reversed direction the new equilibrium path would still have approximately the same distribution of firms as the old path.

Many dispersed equilibria exist because, when average transport costs are high, the profit effect dominates the consumer effect and demand is predominantly local. First, since average transport costs are high, the price levels are high resulting in a large demand for locally made manufactures. Firms locate such that they can maximize their share of the profit opportunities, which means locating away from other firms. When every firm has this motivation, dispersion results. Second, exporting goods is expensive for all firms and so firms are primarily competing with firms in the same region. Firms are heterogeneous only in their transport cost, meaning that for a given region all manufacturing goods are sold at the same domestic price. These two facts imply that one firm is virtually a substitute for another leading to multiple equilibria with similar proportions of firms, but with one or more firms swapping locations.

The many dispersed and unstable equilibria converge to a stable equilibrium as average transport costs decline because demand becomes more inter-regional. As exports become a more viable source of profit, firms are no longer a substitute for one another. Some firms are more apt to deal with local competition than others and these differences render slight permutations on an equilibrium untenable.

IV.b. Smooth transition to agglomeration 
The transition between equilibrium distributions is almost always smooth as transport costs decrease. Standard results often show that there exists a critical transport cost at which the stable equilibrium suddenly switches from dispersion to agglomeration. My results do not exhibit this catastrophic agglomeration property as dispersed equilibria continuously transform to agglomeration equilibria as transport costs lower. As a result, a full spectrum of distributions of firms is observed, whereas the standard results only offer three distributions, $0,0.5$ and 1.0 over the entire range of transport costs. Further, entrepreneurs relocate at an increasing rate as transportation costs decline. ${ }^{10}$ The one exception to smooth transition is the perfectly symmetric equilibrium path. Around an average transport cost of 2.5 , the symmetric equilibrium ceases to exist and that path abruptly shifts to one of the stable paths that are converging towards agglomeration. This shift is somewhat analogous to catastrophic agglomeration.

Agglomeration occurs because the consumer effect eventually dominates the profit effect for all entrepreneurs. An entrepreneur considering relocating to the region with more firms must weigh the benefits of cheaper prices and lost profits. As transportation costs decline, the profit differential between the two regions diminishes. This decline in lost profit from relocation causes the consumer welfare effect to become more important and locating near other firms becomes a net benefit for the entrepreneur.

Agglomeration evolves slowly and continuously in this model, as opposed to catastrophically, because the magnitudes of the two effects are different for each entrepreneur. Because of transport cost differences, the consumer welfare effect overcomes the profit effect at different times for different entrepreneurs. Thus,

\footnotetext{
${ }^{10}$ This result is not common for all distributions of transport costs. The shape of the equilibrium path can be quasi-concave, quasi-convex or linear. However, when transport costs are uniformly distributed, results are always similar to those in Figure 1.
} 
entrepreneurs find it optimal to relocate to the agglomeration region at different levels of transport cost.

IV.c. Spatial sorting

Though the spatial distribution of firms is an important result and the focus of most NEG literature, my model shows that a firm's transport cost directly influences their location decision. In order to understand the location decisions of an individual firm, we must look at the disaggregated results of an equilibrium path. Figure 2 shows the location of every firm for an entire equilibrium path. The leftmost column is the firm number. The top row is the base transport cost. A firm's total transport cost is equal to the base transport cost plus 0.01 times one minus the firm number. The number 1 indicates that that firm is located in Home and 0 indicates Foreign. I have also shaded the foreign cells grey to make the patterns easier to see. 
Base transport cost

$\begin{array}{lllllllllllllllllllllll}\text { Firm } & 0.7 & 0.8 & 0.9 & 1.0 & 1.1 & 1.2 & 1.3 & 1.4 & 1.5 & 1.6 & 1.7 & 1.8 & 1.9 & 2.0 & 2.1 & 2.2 & 2.3 & 2.4 & 2.5 & 2.6 & 2.7 & 2.8\end{array}$

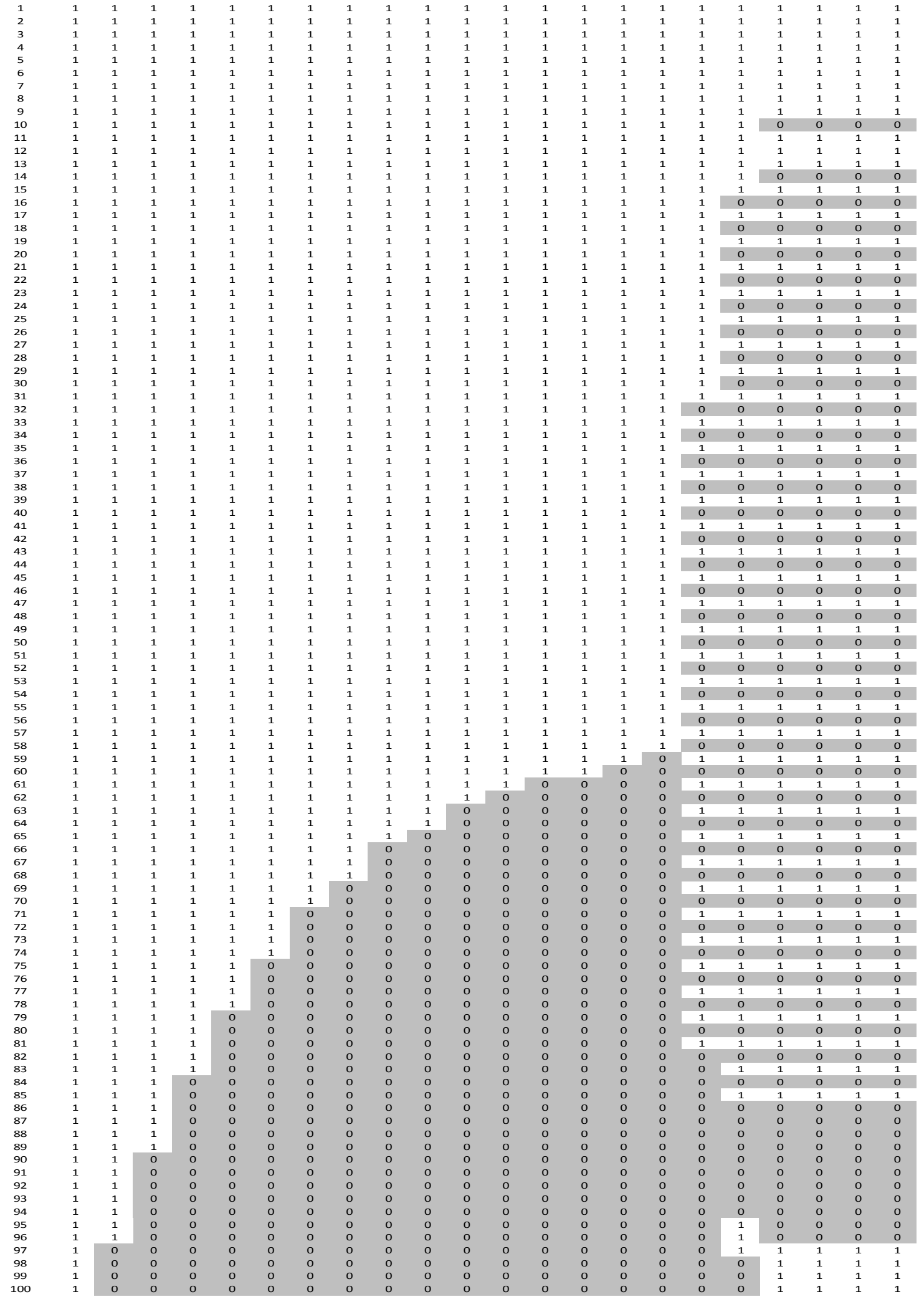

Figure 2. This figure shows firm location for an entire equilibrium path. Home $=1$ and Foreign $=0$ (and grey shaded). A firm's transport cost is equal to the base transport cost (top row) plus .01 times one minus the firm number (column 1). 
As transport costs decrease, firms spatially sort themselves by transport cost. This eventually leads to a bifurcation of firms, where one region is populated by the firms with the lowest transport cost and the other region has the remaining high cost firms. In figure 2, firms are sorted by a base transport cost of 2.2. Firms do not sort themselves immediately while still at high average transportation costs and the sorting happens at different transport costs for different equilibrium paths. All stable equilibrium paths are sorted. However, unstable equilibria do exist in which firms are sorted (at high average transport costs). In figure 2, the distribution at base transport cost 2.2 is unstable, but is stable by 2.1. Around the same time as equilibrium paths converge to one another, the complete sorting occurs. Sorting and convergence do not necessarily occur together and do not happen at the same transport cost for all equilibrium paths.

Figure 2 also demonstrates two more results. First, once the firms are sorted, they stay sorted as transport costs decline. This implies that the firm with the lowest relative transport cost in the high transport cost region will be the first to relocate when transport costs fall. Second, the region which establishes itself as the low transport cost region (Home, in figure 2) will eventually be the region of agglomeration.

Spatial sorting occurs because each firm faces the same location problem and the relative importance of the consumer effect and the profit effect are similar for firms with similar transport costs; thus, they will likely locate in the same region. There are no externalities or other means by which firms with like transport costs benefit from locating near each other. As discussed in the introduction, heterogeneities often serve as dispersion forces in NEG models. In this model, the heterogeneities affect how agglomeration happens, but not if it happens. 
Agglomeration develops in the low transport cost region because the low transport cost firms are better able to maintain profits when local competition is strong. Low transport cost firms use exports to compensate for lost domestic profit due to greater competition. However, high transport cost firms can not export cheaply and are best off locating where fewer firms exist in order to capitalize on local demand. The demand function is increasing in the price index, so by locating in a region with a high price index, a firm makes its own product more attractive to local consumers. This logic also explains why relatively lower transport cost firms in the non-agglomeration region relocate to the agglomeration region before the relatively higher transport cost firms.

The fact that the larger region contains the low transport cost firms somewhat contests Amiti (1998). Her model shows that when two regions are of a different size and there are two industries with different transport costs, the high transport cost industry disproportionately locates in the large region. There are many differences between the models, critical being that there is no agglomeration in Amiti (1998) ${ }^{11}$ and the size of the regions develops endogenously in my model. With no agglomeration, firms will always face the same level of local competition and thus it is efficient for high transport cost firms to locate close to the larger source of demand. With agglomeration, however, local competition will increase for some firms and I find that low transport cost firms are best able to cope with that competition.

\section{Conclusion}

\footnotetext{
${ }^{11}$ Nor should there be agglomeration; Amiti (1998) is not a model of geography. The reasons that agglomeration does not occur are 1) labor is immobile and 2) the returns to capital are spent where they are endowed.
} 
This model adds to the NEG literature by showing that NEG models can accommodate heterogeneous transport costs and these additions complement and enhance existing results. The opposing motivations of the entrepreneurs and the heterogeneities of the model clearly explain the novel results.

Future work could go in several different directions. Most interesting would be an empirical test of this model's predictions. However, at least at the moment, this is subject to data limitations discussed in section 1. On a theoretical front, it would be interesting to examine the effects of positive agricultural transport costs coupled with heterogeneous manufacturing transport costs, in line with Davis (1998). Finally, any subsequent NEG model could incorporate heterogeneous transport costs as an additional level of realism, though this would almost certainly preclude analytical solutions. 


\section{References}

Alonso-Villar O (2005) The effects of transport costs revisited. Journal of Economic Geography 5: 589-604

Alonso-Villar O (2008) A model of economic geography with demand-pull and congestion costs. Papers in Regional Science 87: 261-276

Amiti M (1998) Inter-industry trade in manufactures: Does country size matter? Journal of International Economics 44: 231-255

Anderson JE, van Wincoop E (2004) Trade costs. Journal of Economic Literature 42: 691-751

Baldwin R, Forslid R, Martin P, Ottaviano GIP, Robert-Nicoud F (2003) Economic Geography and Public Policy. Princeton University Press, Princeton, NJ

Baldwin R, Okubo T (2006) Heterogeneous firms, agglomeration and economic geography: spatial selection and sorting. Journal of Economic Geography 6: 323-346

Davis DR (1998) The home market, trade, and industrial structure. American Economic Review 88:1264-1276

Forslid R, Ottaviano GIP (2003) An analytically solvable core-periphery model. Journal of Economic Geography, 3: 229-240

Fujita M, Mori T (2005) Frontiers of the new economic geography. Papers in Regional Science, 84: 377-405

Hummels D (2001) Toward a geography of trade costs. working paper, Purdue University

Krugman PR (1991) Increasing returns and economic-geography. Journal of Political Economy 99: 483-499

Lanaspa LF, Sanz F (2001). Multiple equilibria, stability, and asymmetries in Krugman's core-periphery model. Papers in Regional Science 80: 425-438

Murata Y (2003) Product diversity, taste heterogeneity, and geographic distribution of economic activities: Market vs. non-market interactions. Journal of Urban Economics 53: 126-144

Neary JP (2001) Of hype and hyperbolas: Introducing the new economic geography. Journal of Economic Literature 39: 536-561

Ottaviano GIP, Tabuchi T, Thisse JF (2002) Agglomeration and trade revisited. International Economic Review 43: 409-435 
Pflüger M, Südekum J (2008) A synthesis of footloose-entrepreneur new economic geography models: When is agglomeration smooth and easily reversible? Journal of Economic Geography 8: 39-54

Puga D (1999) The rise and fall of regional inequalities. European Economic Review 43: 303-334

Rossi-Hansberg E (2005). A spatial theory of trade. American Economic Review 95: 1464-1491

Tabuchi T, Thisse JF (2002) Taste heterogeneity, labor mobility and economic geography. Journal of Development Economics 69: 155-177

Venables AJ (1996) Equilibrium locations of vertically linked industries. International Economic Review 37: 341-359

Zeng DZ (2008) New economic geography with heterogeneous preferences: An explanation of segregation. Journal of Urban Economics 63: 306-324 


\section{Appendix}

For all equilibrium paths shown in Figure 1, $\mathrm{N}=100$. For transport costs, I defined two parameters, a base transport cost and the range of transport costs, R. From section 2, $\mathrm{R} / \mathrm{N}$ is the difference between two consecutive firms' transport costs. To calculate an individual firm's transport cost, the formula would be $\tau_{i}=($ base transport cost $)+R / N *(i-1)$. For example, if the base cost $=1$ and $\mathrm{R}=1$, then firm 1's cost would be 1.0, firm 2's cost would be 1.01, firm 3's cost would be 1.02 and so on. The results in the paper are presented in terms of average transport cost. The average is simply calculated as (base transport cost) $+.495 * \mathrm{R}$.

When determining an equilibrium path, the base transport cost was decreased in increments of 0.1 . In two cases, 1) the symmetric equilibrium changing to a sorted path and 2) the point of complete agglomeration, I used increments of 0.01 to determine the exact point of occurrence.

The parameter for the equation of motion, $\theta$, was set equal to 0.1 , meaning a maximum of $\theta^{*} \mathrm{~N}=10$ firms could relocate per iteration. However, the simulation had trouble converging in some cases. I set $\theta=0.1$ conditional on being in the first 15 rounds of iteration, after that motion was restricted such that only one firm could move each round. Most of the time, convergence would occur before this point. The results were not meaningfully changed if a different value of $\theta$ is used as long as the additional restriction past 15 rounds is used. For larger values of $\theta$, there are some transport costs for which the program never converged without the additional restriction.

$N=100$

The specific values going into the results shown in Figure 1 and 2 are:

$\mathrm{L}=500$

$a=60$

$b=1$

$c=0.5$

$a_{A}=1$

$a_{M}=0.3$

$R=1$

$\theta=10 \%$ 